\title{
TECNOLOGIA DIGITAL: A NECESSIDADE DA CONSTRUÇÃO CRÍTICA- CONSEQUENTE DE UM NOVO ETHOS HUMANO
}

\section{DIGITAL TECHNOLOGY: THE NEED OF CRITICAL CONSEQUENT NEW HUMAN ETHOS}

\author{
Franco Maximiliano Rodríguez
}

\begin{abstract}
RESUMO
Neste artigo pretendo apontar para a necessidade "ética" de um uso "crítico consequente" das tecnologias digitais. Visando esse objetivo central, farei algumas observações sobre aquilo que entenderei como a atual construção social de um novo ethos no marco da nossa sociedade digital global. Na primeira parte do artigo, avanço algumas teses para a defesa daquilo que chamo de naturalização do exótico. Nela, coloco em questão a mudança ética das pessoas, que traslada a esfera do tecnológico digital e virtual para o território do cotidiano, e que, consequentemente, desloca o tradicionalmente natural para o campo do exótico. Em seguida, analiso também as consequências psicológicas e sociais que essa mudança acarreta no nosso ethos. $\mathrm{Na}$ segunda parte do artigo, abordo as tensões existentes entre as novas tecnologias, as redes sociais e a prática docente a partir de depoimentos de professores e outros profissionais sobre esse tema. Finalmente, faço uma distinção entre éticas que chamarei de acríticas, acráticas e críticas consequentes para, em um último momento, tecer algumas considerações finais sobre o tema em questão.
\end{abstract}

Palavras-chave: Crítica. Tecnologia. Digital. TICs. Educação.

\begin{abstract}
In this article, I intend to demonstrate the "ethical" need of a "consequent critical" use of digital technologies. To this end, I make some claims on what I understand as the current social construction of a new ethos in our global digital society. In the first part of the article, I defend some arguments related to what I call the naturalization of the exotic. I question the ethical change in people when the virtual, digital and technological sphere enters into the realm of everyday life, bringing what is traditionally considered to be natural into the sphere of the exotic. Next, I analyze the psychological and social consequences of this change in our ethos. In the second part, I approach the existing tensions between new technologies, social networks and teaching practices based on the testimonies of teachers and other professionals on this issue. Finally, I distinguish three kinds of ethics, which I call uncritical, akratic and consequent-critical, and make some final remarks on this issue.
\end{abstract}

Keywords: Critique. Technology. Digital. ICTs. Education.

"Doutorando em Filosofia - UFSC 


\section{Introdução}

O presente artigo tem por objetivo defender a tese de que o uso das tecnologias digitais deve ser "crítico consequente". Não obstante, para compreender o que isso significa, será preciso acompanhar a discussão apresentada a seguir, ou pelo menos, ate a seção intitulada "Acrítico, acrático e crítico consequente”. Contudo, ainda é possível adiantar que, no presente artigo, pretendo abordar algumas das principais características daquilo que chamamos de cultura digital, isto é, o tipo de sociedade na qual vivemos hoje, visando sempre uma abordagem crítica. Trata-se de um trabalho que visa à análise de fatos atuais, muitos dos quais fazem parte de um verdadeiro processo de mudanças éticas cujo desenlace não podemos prever com total clareza.

Feitos esses esclarecimentos, passo agora a falar sobre o perfil do artigo. Começo por dizer que se trata de uma abordagem sobre a "ética" do homem inserido naquilo que se costuma chamar de cultura digital. No entanto, é preciso especificar o que se deve entender por "abordagem sobre a ética". Para cumprir essa tarefa, cabe fazer uma rápida especificação conceitual. Do ponto de vista etimológico, os termos "ética" e "moral" significam a mesma coisa. A única diferença é que a primeira provém do Grego Clássico e a segunda do "Latim". Originalmente, ambas as palavras eram utilizadas por gregos e romanos, respectivamente, para se referir aos costumes das pessoas. Sendo assim, pode-se observar que o uso que hoje conferimos a esses termos não corresponde ao original. Nos tempos atuais, quando falamos sobre a ética ou moral de uma pessoa, instituição etc., fazemos referência a outros elementos da vida humana que vão muito além de meros costumes. Mas foquemos nossa atenção na palavra "ética”. Certamente ela não é sinónimo de "Ética". Da mesma forma que "história" e "História" não são sinônimos, também podemos dizer que "ética" e "Ética" não se referem a um mesmo objeto. No primeiro caso, podemos definir história - mesmo que de forma muito obtusa - como uma longa concatenação de eventos que aconteceram no mundo, enquanto História é a disciplina que tem por objeto de estudo esses eventos. De forma análoga, enquanto a ética se refere a um determinado objeto, a Ética — da mesma forma que a História- é simplesmente uma discipli- na. Mas, para os fins do presente trabalho, o que vou propor é que se entenda que, à diferença da História, que tem por objeto seu homónimo com inicial minúscula, a Ética -isto é, a disciplina- tem por objeto de estudo a moral e não a ética. Desse modo, o que aqui vou propor é que utilizemos o termo "ética" no sentido originário empregado pelos gregos, isto é, como sinônimo de "costume". O motivo é que, dessa forma, teremos a possibilidade de utilizar o conceito de ética de uma forma muito diferente do uso que hoje fazemos do conceito de moral. No caso desta última, ela seguirá sendo entendida como o comportamento do indivíduo em relação aos seus deveres. Assim, grosso modo, podemos dizer que a Ética, cujo objeto é a moral, se encarrega de refletir sobre quando um indivíduo ou grupo age de forma correta, tendo como critério um determinado conjunto de deveres ${ }^{1}$. Em contraposição, o termo "ética" referir-se-á a aspectos puramente comportamentais dos seres humanos, os quais não estão associados a deveres ${ }^{2}$.

A partir dessa distinção, é possível retomar os objetivos do presente trabalho, o qual visa propor uma abordagem sobre a "ética" dos seres humanos inseridos na cultura digital. Isso significa que o que aqui faremos não serão julgamentos morais sobre o comportamento do homem da cultura digital —não diremos que quem tem uma relação $\mathrm{X}$ com as tecnologias digitais age de forma imoral. $\mathrm{O}$ objeto de nossos julgamentos será o comportamento —os hábitos- dos seres humanos que convivem diariamente com a tecnologia digital, sem, contudo, entrarmos na esfera dos valores morais.

Como último esclarecimento introdutório, cabe destacar que este artigo apresenta uma abordagem de caráter filosófico sobre o tema. Nesse sentido, o trabalho está baseado, além das informações obtidas a partir da experiência como tutor no curso de formação de professores com foco no uso das

\footnotetext{
${ }^{1}$ Certamente não pretendo aqui realizar uma exposição sobre a Ética como um todo, visando uma reflexão sobre suas diferentes subáreas, tais como a Ética normativa, a Ética aplicada, Ética médica, Ética profissional etc. Segundo os propósitos do presente trabalho, acredito que seja suficiente oferecer uma definição vaga da Ética como disciplina, dado que ao longo do artigo ela não ocupará nossa atenção nem de forma tangencial.

${ }^{2}$ A partir da estratégia de diferenciar no uso "ética" e "moral" da forma explicitada, podemos dizer que todos os seres humanos possuem uma determinada ética. Uma vez que a ética não está mais associada ao cumprimento de deveres - como é o caso da moral- podemos afirmar, por exemplo, que mesmo um bandido ou um grupo deles — um bando- possui certa ética ou certo ethos, a saber, uma ética ou um ethos delitivo.
} 
tecnologias digitais na educação, em resultados de diversos trabalhos de campo realizados por outros pesquisadores. Ademais, é importante salientar que o presente trabalho não se vincula de forma específica a uma tradição filosófica, seja ela de viés marxista, kantiano, hegeliano ou outro qualquer. A razão principal para esse posicionamento —embora não seja a única- consiste em que a utilização de um determinado marco teórico-referencial clássico antigo nem sempre representa a melhor estratégia para a análise de aspectos tão singulares da nossa época.

Uma vez feitos de forma sintética tais esclarecimentos, passo a apresentar a estrutura do texto. Dividirei o trabalho em três blocos diferentes. O primeiro pretende ser uma aproximação do novo ethos do homem da cultura digital. Ela estará dividida em várias subseções, cada uma das quais visa analisar um aspecto do referido ethos. A segunda parte abordará alguns dos principais efeitos negativos do uso não apropriado das tecnologias digitais no marco da educação. Para isso, farei algumas considerações a partir do trabalho do Professor britânico Mark Fisher e analisarei a informação coletada em entrevistas por mim realizadas no contexto da função de tutor no curso acima especificado. Na terceira e última parte, apresentarei as principais teses do trabalho, esperando que elas estejam corretamente fundamentadas pelas considerações realizadas nas seções anteriores.

\section{NATURALIZAÇÃO DO EXÓTICO}

\section{Não revolução na área do transporte e revolução nas comunicações ${ }^{3}$}

Em abril desse ano, uma das tantas obras de arte do famoso grafiteiro britânico de pseudônimo Banksy causou um forte impacto entre os moradores da cidade de Bristol. Sua criação, hoje conhecida como Mobile Lovers retrata a curiosa cena de dois amantes abraçados na rua, enquanto cada um deles está mexendo no seu celular ${ }^{4}$. O impacto desse trabalho artístico foi tão brutal que, para favorecer sua preservação, foi removido para ser exibido no Bristol Museum \& Art Gallery. Mas qual é o

\footnotetext{
${ }^{3}$ As reflexões da introdução sobre a obra de Banksy foram inspiradas pelo trabalho do pesquisador brasileiro Dennis Donato Piasecki.

${ }^{4}$ A fotografia de Mobile Lovers está disponibilizada em inúmeros sites em Internet. Para conhecer maiores detalhes sobre o impacto da pintura, veja Banksy's...(2014).
}

motivo pelo qual essa expressão artística causou tanto impacto? Certamente, o cenário no qual ela foi plasmada não foi um fator determinante, dado que a pintura foi realizada numa rua escura de Bristol. O que impacta na cena retratada é que ela evoca uma situação corriqueira do nosso dia a dia, na qual duas pessoas não conseguem se desconectar dos seus aparelhos celulares, nem para se beijar ou simplesmente se abraçar. Impacta também perceber que, alguns anos atrás, esse tipo de grafite seria considerado uma fotografia de um filme de ciência ficção; uma visão imaginária sem correspondência nenhuma com a realidade.

Banksy nos leva a refletir sobre as mudanças que nossas sociedades contemporâneas sofreram. Quando assistimos filmes antigos ou séries de TV futuristas da década de $60,70,80$ e até 90 , podemos observar que os diretores pintavam um hipotético terceiro e quarto milênios nos quais o progresso científico nos levaria principalmente a desenvolver incríveis meios de transporte; carros voadores que andam pela cidade como moscas de aço — tal como acontecia na série animada The Jetsons de 19621963-; máquinas espaciais que permitiriam ao ser humano viajar a outros planetas sem grande demora —dentro dos quais a série Star Trek de 1966 e todos seus filmes são um claro exemplo ${ }^{5}$. Mas se esses filmes e séries tivessem a verdadeira pretensão de serem vaticínios das nossas sociedades futuras, eles estavam claramente errados. O certo é que o avanço tecnológico até agora alcançado no começo do século XXI não nos permite viajar para outros planetas e galáxias no mesmo tempo que leva uma conexão aérea São Paulo/Paris. Contudo, o que nenhum desses clássicos da TV e do cinema parece ter vaticinado é o avanço quase descontrolado das tecnologias digitais da área da comunicação acontecido no final do Século XX. Eles não conseguiram retratar que, da mesma forma que nos séculos XVIII e XIX a máquina a vapor se apresentou como a novidade tecnológica, possibilitando o desenvolvimento de meios de transporte mais eficientes, nossa sociedade pós-queda do muro direcionaria o avanço tecnológico de forma preponderante no campo da comunicação.

\footnotetext{
${ }^{5}$ Em décadas posteriores, o cinema ainda manteria uma visão futurista a la Jetsons. Eis o caso de Blade Runner de 1982.
} 
No caso particular dos Jetsons - a versão antagônica dos Flinstones - observamos que os produtores da Hanna-Barbera imaginaram cidades do futuro suspensas no ar e casas equipadas com uma imensa quantia de aparelhos eletrônicos, inclusive robôs humanoides ao serviço dos seus amos -ingenuidade que inspiraria o espírito satírico de Matt Groening e que daria origem a Futurama. Não obstante, nas cenas onde George, o pai da família, aparece em seu trabalho, podemos apreciar que o computador no qual ele opera tem vários metros de extensão ${ }^{6}$. A partir de The Jetsons e produções similares, podemos conhecer qual era o imaginário sobre as sociedades do futuro da sociedade dos anos 60 — década na qual já existiam MIG21 soviéticos supersônicos que bombardeavam e jogavam Napalm nas selvas do Vietnam e na que o homem chegaria a visitar a lua numa Apollo. Segundo tal imaginário, as comunidades humanas dos próximos anos —décadas, séculos - operariam com uma vasta gama de meios de transporte, robôs e eletrodomésticos caseiros. No entanto, na década de 1960, claramente não existia nem a suspeita remota dos grandes desenvolvimentos tecnológicos na área da comunicação.

\section{Tecnologia digital e cultura digital}

Quando se fala em tecnologia digital, existe uma verdadeira incerteza sobre o que engloba o digital. Afinal de contas, todo tipo de tecnologia eletrônica é ou foi sempre digital? A expressão digital deriva do Latim dígitum, dedo; essa é a parte cliché e conhecida. Porém, o que nem sempre é conhecido é que digital se refere a um sistema de programação e transmissão de dados através de uma - papo de programador- "lógica binária". O digital surge como substituto do analógico. Sendo assim, dizer que uma tecnologia seja digital não equivale a dizer que se trata de um aparelho eletrônico, tal como é utilizado comumente. Originalmente, transmissões de rádio, de $\mathrm{TV}$, e inclusive a tecnologia celular, eram tecnologias analógicas. A tecnologia digital foi, aos poucos, ganhando seu espaço no mundo da engenharia para, logo, se tornar a tecnologia predominante no mundo das telecomunicações.

\footnotetext{
${ }^{6}$ Para uma compreensão apropriada do tema aqui analisado, vale a pena ver o vídeo elaborado por alguns professores da USP. Veja Jetsons...(2011).
}

Mas se, do ponto de vista técnico, o adjetivo "digital" conota uma forma de programação e transmissão de dados, quando alguém afirma que, hoje em dia, vivemos numa "era digital", certamente não está fazendo referência à tecnologia programática envolvida nas nossas máquinas atuais. O que está fazendo, ou pelo menos assim o entendo, é referência a algo bem mais básico, a saber, a uma forma de conduta humana em particular que envolve certa tecnologia. A era ou cultura digital tem lugar com o surgimento de infinitos aparelhos eletrônicos que possibilitam ao ser humano compartilhar informações em níveis sem precedentes. São esses aparelhos eletrônicos que nos permitem, entre outras coisas, tirar uma foto e compartilhá-la com grande parte da humanidade em poucos segundos. São esses elementos do nosso dia a dia que, à diferença de todas aquelas tecnologias de transporte vaticinadas para o futuro, há poucos anos não existiam sequer no imaginário das pessoas. Nossas sociedades estão verdadeiramente inseridas no marco da tecnologia digital, isto é, sociedades nas quais grande parte do cotidiano está marcado pelo uso de aparelhos que, entre outras coisas, contam com o potencial de nos comunicar com o outro lado do planeta de forma instantânea. Mas se essa nova tecnologia que está tão presente no nosso dia a dia, prima facie, parece expandir nosso espectro de capacidades comunicativas ao máximo, por que ela, ao mesmo tempo, gera um receio tão forte? Em outras palavras, se o uso de aparelhos celulares, computadores, smartphones etc., de fato, pode chegar a expandir nossa liberdade e autonomia através de um fluxo quase ilimitado de informação, por que tantas pessoas no mundo hoje reagem contra nossa nova, digamos, forma de vida? ${ }^{7}$ Avancemos na tentativa de responder estas simples questões.

\section{Facebook e o ethos da conexão nas redes sociais}

Em fevereiro de 2004, a Facebook Inc., empresa então minúscula fundada por quatro adolescentes, criou a rede social mais influente

\footnotetext{
${ }^{7}$ É a própria tecnologia digital que nos permite, por meio do acesso a internet, conhecer um número tão grande de depoimentos de profissionais de diversas áreas do conhecimento, principalmente das áreas da educação e da psicologia, contrários ao uso quase contínuo de aparelhos eletrônicos destinados à comunicação entre pessoas.
} 
do começo do Século XXI. The Facebook, como inicialmente foi chamada, foi pensada como uma rede que estaria aberta unicamente para estudantes da Universidade de Harvard. Foi só um tempo depois que também passou a ser usada por outras universidades estadunidenses. O que começou como um projeto piloto para a interação de estudantes universitários dos Estados Unidos passaria logo a ser uma rede social aberta para toda pessoa maior de 13 anos de idade ${ }^{8}$. Em 2008, o Facebook atingiu a marca recorde de 100 milhões de usuários; em 2010, eram mais de 500 milhões. Já em 2012, o número de usuários superou um bilhão ${ }^{9}$. Com o Facebook, nossa cultura digital alcança um dos seus maiores traços identitários; ela se consagra como uma sociedade na qual seus membros estão ou, mais do que isso, sentem a necessidade de estar "conectados".

Esse novo costume de estar ligado a uma rede social, é claro, vem sendo explorado por empresas e partidos políticos há certo tempo. Hoje pareceria pouco estratégico que o dono de um bar, de uma pizzaria, uma firma etc., não possuísse uma página de Facebook para promover seu negócio. Resulta difícil cogitar a possibilidade de uma campanha política em que as redes sociais não joguem um papel determinante ${ }^{10}$. O uso do Facebook, da mesma forma que outras tantas redes sociais, tornou-se um elemento absolutamente popular nos nossos dias. Isso fica claramente evidenciado entre aqueles que optam de forma reflexiva por não ter uma conta na rede social. Todo aquele que não possui Facebook deverá necessariamente explicar, geralmente para pessoas quase chocadas, o motivo que o levou a não tê-lo. ("Mas como que tu não tens Facebook? Tu és

\footnotetext{
${ }^{8}$ Mas, como todos sabemos, a restrição etária do uso do Facebook é meramente formal. Em maio de 2011, a Consumer Report publicou que pelo menos 7.5 milhões de usuários eram menores de 13 anos. Veja Fox 2011.

${ }^{9}$ Veja Facebook (2012).

${ }^{10}$ Em 2011, Braga publicou um artigo que trata dos efeitos do uso de redes sociais nos processos eleitorais no Brasil, principalmente focando sua atenção nas eleições presidenciais de 2010. Nesse trabalho, o autor conclui a partir de seu trabalho de campo que o papel das redes sociais nas referidas eleições no Brasil difere de forma significativa em relação ao evidenciado nas eleições estadunidenses de 2008. Veja Braga (2011). Além de ser um ótimo trabalho sobre o impacto de redes sociais nas eleições 2010, o artigo possui o mérito de possibilitar a observação das mudanças éticas dos eleitores brasileiros nos últimos quatro anos. Se é possível afirmar que o uso de redes sociais não foi de grande magnitude nas eleições presidenciais brasileiras de 2010, dado que o debate não foi transferido para essa esfera, no caso das eleições de 2014, foi visível o aumento do debate político em redes tais como Facebook.
}

louco?"). Esse tipo de questionamento evidencia que o interrogador não concebe que, hoje em dia, exista a possibilidade de levar adiante uma vida digna de ser vivida sem pertencer a uma rede social.

Mas se o fenômeno Facebook parece ser um dos traços mais fortes das nossas sociedades atuais, ele também representa um claro caso em que discurso e realidade não são correspondentes. A conexão a uma rede social — seja ela constante ou não- é comumente interpretada como uma necessidade. E quem não acreditar nisso pode fazer seu próprio "trabalho de campo": interpele um grupo de amigos e pergunte a eles por que passam tanto tempo conectados ao Facebook, inclusive em horas de trabalho ou até mesmo quando estão enroscados num abraço com seu parceiro - tal como retratado na pintura de Banksy. As justificações oferecidas para seu ethos podem ser várias. Muitos argumentarão que precisam estar conectados para não perder o contato com seres queridos que estão longe. Outros dirão que utilizam o Facebook e outras redes sociais para economizar dinheiro nas suas contas telefônicas, poupando-se de realizar constantes ligações ou enviar SMS. Mas isso não justifica as muitas horas nas quais esses usuários permanecem conectados, vendo, comentando e curtindo fotos e vídeos. Tampouco - muito menos- justifica o fato de que, nos últimos anos, os usuários de Facebook tenham optado em massa por postar fotos instantâneas de coisas corriqueiras do dia a dia como, por exemplo, a imagem de um prato de comida, com comentários, tais como: "Mmm, delícia!"11. Dificilmente poderíamos dizer que uma pessoa precisa ou necessita passar horas conectados realizando esse tipo de atividades. Elas claramente

\footnotetext{
${ }^{11}$ A produção de vídeos e fotos utilizando câmeras digitais de celulares é mais uma atividade popular crescente própria dos últimos dois anos. Nos nossos dias, podemos apreciar o grande hábito que as pessoas possuem de tirar fotos e fazer vídeos, simplesmente, de tudo. No Brasil, o hábito de fotografar tudo para, logo, ter material para postar em Facebook, causou, em 2013, a eliminação de 47 candidatos do ENEM. Recentemente, nas provas do ENEM de 2014, o número de desclassificados por postarem fotos de provas em redes sociais aumentou para 65 . Veja Enem...(2014). No Brasil, os processos eleitorais para as eleições presidenciais do presente ano foram marcados por usos indevidos das câmeras de celulares. No Artigo 88 da Resolução $\mathrm{n}^{\circ} 23.999$, o Tribunal Superior Eleitoral proibia o eleitor de portar aparelho de telefonia celular, máquinas fotográficas, filmadoras, equipamento de radiocomunicação, ou qualquer instrumento que possa comprometer o sigilo do voto, devendo ficar retidos na Mesa Receptora enquanto o eleitor estiver votando”. Veja Brasil...(2014). Não obstante, mesmo com a punição que poderia chegar a ser de dois anos de detenção, houve muitos casos de pessoas que abertamente postaram selfies em Facebook tiradas ao lado da urna eletrônica.
} 
respondem a meros desejos dos agentes, mas não a verdadeiras necessidades ${ }^{12}$.

A conexão constante a redes sociais parece carregar consigo a promessa de experiência de prazer instantâneo. Estar conectado dá prazer constante, efémero, fugaz e, sobretudo, viciante. Uma vez que a pessoa com o costume de "mexer na sua conta" se conecta, ela não pode sair, ou experimentará uma abrupta sensação de perda de prazer. Para continuar recebendo essa constante estimulação por parte desse espaço virtual por ela criado, não pode se desligar dele. Ela deve estar constantemente fazendo parte desse mundo virtual, seja postando uma foto instantânea, curtindo a foto de um colega, ou simplesmente visitando os links e vídeos que seus amigos postaram no último minuto. É nesse ponto que a pessoa se torna "viciada"; temos agora um hedonista acrítico ou acrático. Ou bem ele não reflete sobre os possíveis efeitos prejudiciais de estar conectado a uma rede social, ou ele já não consegue dar um stop no uso do seu aparelho celular ou computador, muito embora possa, em alguns momentos, perceber que esse novo tipo de ethos está lhe fazendo mal ${ }^{13}$.

\section{Zumbis e Google-glass}

Ruas, metrôs, rodoviárias, aeroportos, são alguns dos lugares das cidades onde diariamente podemos apreciar o novo ethos da nossa cultura digital. Os espaços públicos têm se tornado

\footnotetext{
${ }^{12}$ Perante essa reflexão sobre a conexão quase ilimitada em redes sociais, alguns poderiam chegar a contra argumentar que existem desdobramentos de redes sociais que não possuem o mesmo perfil de Facebook, Twiter etc. Tal seria o caso de Tripadvisor. Certamente pode-se argumentar que quem possui uma conta numa rede social como esta e a acessa regularmente, o faz devido a que ela é útil, isto é, cumpre uma determinada função. No caso do Tripadvisor, ele é muito útil para procurar sugestões sobre praias, restaurantes, hotéis, cidades turísticas etc. Dessa forma, poder-se-ia concluir que quem se conecta a uma rede social procura mais do que simplesmente curtir fotos ou vídeos. Mas essa conclusão é evidentemente precipitada. claro que existem casos nos quais uma pessoa se conecta a numa rede social para diversos fins, entre eles, se comunicar, coletar informação relevante etc. tal como o caso daqueles que se conectam a Tripadvisor. Porém, o ponto é que não se pode concluir que não exista uma diferença substancial entre (1) aquela pessoa que entra nessa rede social procurando um hotel apropriado para uma viagem, ou inclusive entre aquele que se conecta ao Facebook para realizar uma comunicação valiosa com outra pessoa e (2) aquele que passa conectado muitas horas por dia em Facebook, curtindo fotos de forma compulsiva. No primeiro caso, a pessoa procura satisfazer uma verdadeira necessidade, no segundo, a pessoa possui o ethos de estar conectado de forma compulsiva o tempo todo numa rede social.

${ }^{13}$ As explicações para o significado de "acrítico" e "acrático" serão discutidas na terceira parte deste trabalho, quando se abordará as implicações decorrentes de um uso crítico consequente das tecnologias digitais.
}

progressivamente uma área para pessoas cujo comportamento é muito similar ao comportamento de um zumbi. Todas elas transitam nos mesmos espaços públicos, mas cada uma está mais ocupada em atender aos estímulos do seu celular, seu smartphone, do que em responder aos estímulos do seu entorno. É nesses casos que o simples fato de perguntar a hora para um pedestre, torna-se todo um desafio. Quando estamos perdidos, ou não sabemos onde fica a rua do nosso próximo destino, temos muitas vezes a difícil tarefa de decidir dentre um grande universo de "zumbis" qual deles incomodar. Mas como fazer essa escolha quando cada um deles está ou escutando música, ou enviando uma mensagem pelo WhatsApp, ou postando uma selfie que acaba de tirar na porta de um supermercado, ou falando por celular? Para resolver esse tipo de problema, a solução quase trágica parece ser somente uma: comprar o último aparelho com tecnologia GPS e nos tornar também em um zumbi. Pronto, agora estamos em harmonia com o ambiente!

Parece ser indiscutível que o novo ethos de utilizar constantemente aparelhos eletrônicos de comunicação e transferência de dados tem criado o maior número de zumbis da história da humanidade. E a tendência é claramente ampliar a produção de zumbis. Em 2012, a Google começou a realizar uma campanha publicitária no mercado estadunidense da sua última criação, o Google Glass ${ }^{14}$. Pelo menos desde 2006, a empresa vinha trabalhando nesse projeto, que consiste na comercialização de um dispositivo similar a um par de óculos, o qual possui, numa das lentes, uma tela em que o usuário pode realizar diferentes funções, tais como escolher música, consultar mapas, enviar mensagens etc. No primeiro semestre de 2014 foi lançada à venda nos Estados Unidos a versão Beta do produto. $\mathrm{O}$ valor da unidade era de 1.500 dólares.

Google Glass está ainda em fase de testes. No entanto, podemos ter certeza que, mais cedo ou mais tarde, esse produto estará no mercado. E outra coisa da qual podemos ter certeza é que, devido ao funcionamento do mercado tecnológico, ele será um sucesso de venda. Sendo assim, devemos estar preparados para acolher na nossa rotina mais um

\footnotetext{
${ }^{14} \mathrm{O}$ vídeo publicitário original está disponível em Youtube. Veja Google..
} (2012) 
aparelho que promete nos conectar aos espaços virtuais. Embora alguns indivíduos optem por não incorporar esse novo aparelho de imagem futurista em sua vida pessoal, podemos ter certeza absoluta de que em pouco tempo teremos amigos, colegas, companheiros de trabalho etc., usando esses pseudo óculos. Dessa forma, devemos estar preparados para suportar os efeitos de mais uma máquina criadora de zumbis $^{15}$, disputando a atenção daqueles com os quais queremos, simplesmente, conversar, digamos, face to face.

\section{O exótico torna-se natural e vice-versa}

Lembro bem que, em 2004, recebi como presente da minha mãe meu primeiro celular, não digital, mas analógico. O motivo de tal presente era que eu me mudaria da minha cidade no interior para Montevidéu a fim de iniciar meus estudos universitários de Filosofia. Fui a primeira pessoa que conheci a ter celular. Até aquele momento, nunca tinha visto alguém usar um celular. Isso fazia de mim uma espécie de menino vanguardista. No entanto, cabe ressaltar que o aparelho que recebi não contava com a tecnologia GSM, ou seja, não podia enviar SMS. Para falar a verdade, o aparelho nem possuía uma verdadeira agenda. Ele tinha a capacidade de armazenar vinte números de telefone, mas sua tecnologia era tão limitada, que não associava nomes aos números. Em outras palavras, eu podia ter os números de telefone da minha casa, de algum tio etc., mas eu não podia guardar esses números com o nome das pessoas às quais eles pertenciam. Como o leitor imaginará, usar aquele aparelho, no começo, era quase uma raridade. Eu já possuía celular, mas ainda não precisava —nem podia- usá-lo diariamente; para quem ligar, se ninguém tinha celular? Se pararmos para pensar que essa era a realidade de somente dez anos atrás, ficaremos totalmente surpresos pela rapidez com a qual o aparelho celular tornou-se um elemento cotidiano. Hoje, mal conseguimos cogitar a possibilidade de sair de casa sem levar o celular. Aliás, muitas pessoas desistem de realizar programas em lugares onde não há sinal de internet ou onde não há uma tomada para carregar a bateria do aparelho. São as mesmas pes-

\footnotetext{
${ }^{15}$ Claramente essa é a mensagem do vídeo intitulado Google Glass Sucks! Publicado em Abril de 2013, já conta com mais de 14 milhões de visualizações. Veja Google...(2013).
}

soas que, quando estão num jantar, preferem bater papo pelo Tinder com pessoas que estão "curtindo" e comentando suas fotos no "Face" do que conversar com aqueles que estão sentados ao seu lado.

$\mathrm{Na}$ medida em que o enriquecimento da vida virtual da pessoa passa a ser o normal, pode-se observar aquilo que chamarei a naturalização do exóti$c o$, tema que abordarei a seguir.

Existem no Brasil novos empreendimentos que utilizam certos elementos da natureza para o tratamento de algumas doenças crônicas. Um dos casos paradigmáticos é aquilo que foi chamado de Bototerapia. Como o próprio nome do tratamento indica, trata-se de um procedimento que utiliza o golfinho cor-de-rosa da Amazônia como instrumento terapêutico para o tratamento de alguns problemas associados à falta de motricidade de crianças deficientes ${ }^{16}$. O curioso desse tratamento, o qual vem sendo desenvolvido desde 2006, é que ele está puramente baseado na utilização de elementos totalmente naturais, tais como o Rio Amazonas, e os próprios golfinhos. A ideia é muito simples: a criança a ser tratada deve entrar nas águas do rio para manter contato com o golfinho. Grosso modo, ela experimenta o grande prazer de interagir com um animal que não oferece nenhum tipo de risco para sua segurança, o que a estimula para o desenvolvimento de habilidades motoras afetadas pela doença. Mas o ponto que eu gostaria de analisar é em que consiste a grande novidade desse novo conceito de fisioterapia. Certamente, a Bototerapia não representa nada de novo para todo aquele que nasceu perto da beira de um rio. Basicamente, ela está apoiada em atividades corriqueiras que uma grande quantidade de crianças que provêm do interior realizam diariamente, isto é, pular num rio e interagir com animais. Aquilo que é oferecido como um novo conceito em fisioterapia no Brasil, que, nos termos dos profissionais envolvidos "incorpora de forma interdisciplinar elementos de educação e saúde", não é outra coisa senão uma oportunidade para uma criança com deficiências motoras pular num rio enquanto é cuidado por um instrutor para curtir a vida na água ao lado de um bando de golfinhos querendo se alimentar.

Alguns poderão pensar que o caso da Bototerapia representa um exemplo isolado e que

\footnotetext{
${ }^{16}$ Para compreender em que consiste a Bototerapia, veja O boto...(2011).
} 
ele não consiste em um verdadeiro indicador sobre a realidade da(s) nossa(s) sociedade(s). No entanto, cabe destacar que a Bototerapia faz parte de um grupo de novos tratamentos terapêuticos no mundo. Além dele, cabe mencionar o caso de Equinoterapia, método terapêutico que utiliza o cavalo como forma de estímulo direto para o tratamento de pessoas com deficiências físicas ${ }^{17}$. O conceito é o mesmo que no caso da Bototerapia: utilizar um animal para estimular uma criança com problemas motores. Em outras palavras, o tratamento que a criança recebe é a possibilidade de brincar de forma controlada com o cavalo por um curto período de tempo.

Esses tipos de tratamentos, os quais, do ponto de vista do trabalho, não são senão serviços, podem ser interpretados a partir de uma compreensão das caraterísticas da nossa sociedade atual. Que esses serviços, digamos naturoterapêuticos —-muitos dos quais são bastante caros- estejam em alta nos nossos dias, só pode ser explicado a partir de uma alternância entre aquilo que há poucos anos entendíamos como natural e aquilo que se nos apresentava como o exótico. O que tradicionalmente foi concebido como uma simples brincadeira de criança — pular num rio, andar de cavalo - hoje é considerado um tratamento alternativo. Dessa forma, somente as pessoas com deficiências ou portadoras de doenças crônicas estão motivadas a realizar aquele tipo de atividades. $\mathrm{O}$ que outrora era uma prática habitual de meninos, hoje é colocado no marco do clínico. Não chama a atenção o fato de que um profissional da área da saúde sustente que ter um contato com elementos naturais - rio, boto, cavalo etc. - faz bem aos seres humanos. Muito pelo contrário, o curioso é que isso seja colocado como sendo uma grande novidade que só foi revelada na virada do Século XXI por especialistas da saúde.

Fazemos parte de um mundo no qual o natural sofre um claro processo de deslocamento para a esfera do exótico. Os motivos são evidentes. Quanto mais uma pessoa ${ }^{18}$ estiver exposta aos efeitos de uma vida sedentária, próxima de um Playstation, um computador, um celular ou até de uma TV, tanto mais considerará o que outrora fosse natural como exótico. Para essa pessoa pode ser mais normal matar cem mil

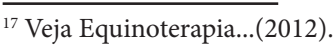

${ }^{18}$ Confesso que a tentação de usar a palavra "criança" em vez de "pessoa" foi grande.
}

zumbis virtuais por dia do que caminhar meia hora fora da sua casa e sentir os raios do sol batendo em sua pele. São aquelas pessoas que precisam que um terapeuta lhes revele uma das grandes verdades ocultas na nossa cultura digital, a saber, que brincar com animais e pular no rio é divertido e que se divertir fazendo atividades tolas na natureza faz bem para o ser humano. Em resumo, essas pessoas podem se sentir muito mais ameaçadas pelos vírus troianos que podem atacar seu computador do que pelo vírus da gripe.

"Vírus", "navegar", "quarentena", "bate papo": expressões com uma origem física, que começaram sendo utilizadas de forma quase metafórica para se referir a elementos associados à tecnologia digital, hoje fazem mais sentido no terreno virtual da internet do que no espaço físico do qual elas provêm. Como explicaríamos a um Júlio Verne que hoje as pessoas, longe de viajar milhares de léguas em submarinos ou de embarcar numa aventura ao centro da Terra, conseguem, na segurança da sua casa, navegar pelo mundo todo, seja até outros continentes, profundezas dos mares, outras galáxias, ou o centro do Sol? Sem falar que aquela conduta quase compulsiva, tão própria de nosso tempo que chamamos de bate papo, não é outra coisa senão o oposto de um verdadeiro batimento de papo, a saber, um puro bate dedo.

\section{TECNOLOGIA DIGITAL E EDUCAÇÃO}

\section{Hedonismo depressivo}

Até aqui, observamos algumas das características da nossa nova cultura digital. Nessa segunda parte do artigo, passaremos a focalizar nossa atenção para um aspecto concreto dessa nova cultura da qual fazemos parte. Analisaremos agora os efeitos da tecnologia digital na esfera da Educação.

Em 2009, Mark Fisher, professor consagrado da Universidade de Londres, publica seu livro Capitalist realism: is there no alternative? Nele, o autor aponta para algumas das principais características da sociedade inglesa contemporânea, atravessada pelos efeitos colaterais de um sistema capitalista neoliberal. Todavia, no quarto capítulo, ele abordará de uma forma sumamente original o problema das patologias sociais dessa sociedade, principalmente, aquela que chamará de hedonismo depressivo. Para compreender a riqueza desse conceito, nada melhor que as próprias palavras de Fisher. 
Muitos dos estudantes adolescentes que eu conheço parecem estar num estado que eu chamaria de hedonismo depressivo. A depressão é caracterizada usualmente como um estado anti-hedonista [of anhedonia], mas a condição a qual estou me referindo não é constituída pela inabilidade de sentir prazer, senão pela inabilidade de fazer qualquer coisa, exceto perseguir prazer (FISHER, 2009 , p. 21-2, primeiro grifo meu, segundo grifo do autor, tradução minha).

Esse hedonismo depressivo do qual Fisher fala, seria, segundo a tese do autor, o resultado do uso constante de tecnologias digitais -celulares, computadores, jogos de vídeos, televisão- e de uma exposição descontrolada de estímulos sensoriais associados a tais tecnologias. Em outra passagem muito esclarecedora, o autor comenta:

Perguntei para um estudante por que ele sempre estava usando fones de ouvido em aula. Ele respondeu que isso não importava, porque ele não estava escutando música. Em outra aula, ele estava colocando [playing] música num volume muito baixo pelos fones de ouvido, mas sem usá-los. Quando eu pedi para ele desligar o aparelho, ele replicou que nem ele podia escutar a música. Por que usar fones de ouvido sem escutar música ou colocar música sem usar os fones de ouvido? Por que a presença dos fones nas orelhas ou o conhecimento de que a música está tocando [playing] (inclusive se ele não podia escutá-la) era a garantia de que matrix estava ainda aqui, ao seu alcance (FISCHER, 2009, p. 24, grifo do autor, tradução minha).

Como deveríamos interpretar a reflexão de Fisher a respeito do uso de aparelhos de som em sala de aula? Acredito que a resposta seja: com a perplexidade e indignação que um professor sente pelo fato de perceber que um número expressivo de seus alunos não podem se desconectar — desgrudarde uma máquina, nem sequer por alguns minutos para assistir uma aula.

É também interessante observar como Fisher não interpreta o hedonismo depressivo como uma patologia social isolada. Muito pelo contrário, segundo nosso autor, ele se conjuga com outros tantos vícios ou patologias das sociedades atuais. Por exemplo, ele defende que esse forte apego por parte dos jovens ao uso irrestrito de tecnologia digital é uma das grandes causas deles não estarem capacitados sequer para ler um livro. Nas suas palavras:
Pedir para os estudantes lerem mais do que um par de sentenças e muitos - e esses são estudantes de primeiro nível - protestarão que eles não podem fazer isto. A desculpa mais frequente que os professores escutam é que é tedioso [boring]. Não é tanto o conteúdo do material escrito o que está em questão aqui; é o ato em si de ler que é considerado tedioso (FISHER, 2009, p. 23, grifo do autor, tradução minha).

O processo educativo como um todo entra numa espécie de círculo vicioso no qual (1) o aluno não estuda, (2) o professor sabe que não pode esperar muito dos seus alunos, (3) o professor se torna menos exigente em relação ao desempenho dos alunos, (4) o professor não sente estímulo para preparar aula, (5) o aluno não é motivado para estudar e prefere passar o dia todo recebendo estímulos dos seus aparelhos eletrônicos. Esse círculo vicioso é tão comum no âmbito da escola -inclusive nas universidades - que qualquer professor que, movido pelo sentimento de dever, quiser colocar um verdadeiro stop nessa situação, preparando a aula de forma apropriada e cobrando dos seus alunos um mínimo de estudo domiciliar, corre o risco de ter que escutar o tempo todo que ele é "muito exigente" e que sua "metodologia" não é apropriada. Surgem assim os novos alunos reivindicadores compulsivos de liberdades e direitos. São aqueles alunos que não titubeiam na hora de criticar o trabalho do seu professor, mas que em nenhum momento demonstram perceber que seu comportamento passivo com relação ao seu próprio processo de educação é o problema central. Chegamos assim a compreender o que Fisher (2009, p. 23) chama de "quadro post-disciplinar" no marco da Educação.

Analisamos aqui o olhar que Mark Fisher possuía da situação dos seus alunos no ano 2009. Não obstante, cabe destacar que o tipo de coisas que incomodava a Fisher era, por exemplo, o fato de que os alunos escutavam música em sala de aula ou que passavam muito tempo na sua casa, assistindo vídeos no Youtube. Cabe destacar, entretanto, que esse diagnóstico do professor sobre aquele momento da Inglaterra foi construído no mesmo ano no qual dois veteranos do Yahoo! fundaram a WhatsApp. Se Fisher parasse para refletir sobre o ethos dos novos alunos de 2014, muito provavelmente seu diagnóstico seria ainda mais crítico. 


\section{Uso de celulares em sala de aula}

Alguém poderia chegar a argumentar que as reflexões de Fisher estão baseadas na sua experiência como professor num determinado país, numa determinada instituição para, dessa forma, invalidar qualquer tipo de analogia entre a realidade dos estudantes adolescentes britânicos e a dos estudantes adolescentes brasileiros. No entanto, a seguir, pretendo desarticular essa objeção a partir da minha experiência como tutor.

Pouco tempo atrás, fiz uma viagem a algumas escolas de Joinville e Papanduva, cidades do interior do Estado de Santa Catarina, a fim de visitar professores de ensino fundamental e médio que participam de um curso a distância da Universidade Federal de Santa Catarina (UFSC) sobre o uso das TICs na Educação, no qual atuo. Foi curioso notar que, em todas minhas as minhas entrevistas com os professores, ouvi depoimentos sobre o uso indevido de aparelhos celulares nas salas de aula por parte dos alunos. Muitos professores relataram as más experiências sofridas com alunos que se conectam a internet durante a aula. Eles lembraram o fato de que, desde 2008, existe no Estado de Santa Catarina, uma lei que proíbe o uso de celulares nas salas de aula, tanto das escolas públicas, quanto das privadas ${ }^{19}$. Chamou a minha atenção que todos os professores conheciam com bastante detalhe a letra da lei em questão; sinal evidente de que eles deviam citá-la constantemente. Das cinco escolas que tive o prazer de visitar, não houve uma na qual os docentes não tivessem passado por alguma situação envolvendo alunos, fazendo uso indevido de celulares. No entanto, o caso mais curioso aconteceu na Escola Alinor Vieira Corte de Papanduva. Nela, os professores relataram o caso de um aluno que pediu para ir ao banheiro e que, já no banheiro, tirou uma foto das suas partes íntimas e a postou no seu Facebook. Este evento motivou os professores a realizar uma assembleia de pais e professores para discutir sobre o tipo de medidas que a escola deveria tomar em relação ao uso de celulares por parte dos alunos. A proposta da direção e do corpo de professores foi que, caso um aluno fosse descoberto usando celular em sala de aula, o aparelho seria "retido" pelo professor e encaminhado para a

\footnotetext{
${ }^{19}$ Trata-se da Lei № 14.363 , publicada no dia 25 de janeiro de 2008 . Veja Santa Catarina...(2008).
}

direção. Todavia, o aparelho só poderia ser recuperado pelo responsável do aluno após o pagamento de uma "multa" cujo valor seria estabelecido na assembleia. O curioso resultado foi que, através de uma espécie de contrato social, os pais dos alunos assumiram o compromisso de responder de forma solidária perante a norma caso seus filhos incorressem na violação da referida pauta estabelecida na instituição. O resultado foi a redação do item 11 das proibições dos alunos, que diz:

- É expressamente proibido o uso do celular na unidade escolar, previsto na lei. $\mathrm{N}^{\mathrm{o}} 14.363 / 08$. Se o aluno insistir em fazer uso do mesmo, o celular será retido pelo professor da aula que entregará na direção. Somente será entregue aos pais ou responsável do aluno (mediante multa de $\mathrm{R} \$ 30,00$ ) Em caso de reincidência o celular será encaminhado à Delegacia e registrado $\mathrm{BO}^{20}$.

O que chama a atenção da medida institucional tomada pela Escola Alinor Vieira Corte não é o fato de a escola ter reivindicado a lei estadual que proíbe o uso de celulares em sala de aula. De fato, antes da celebração da Assembleia de pais e docentes, já existiam no Plano Político Pedagógico da escola referências explícitas à Lei 14.363. Chama a atenção que, desta vez, os professores sentiram a necessidade de desestimular o uso de celulares em sala de aula, apelando para algo além do discurso estritamente moral $^{21}$. Eles não fizeram uma campanha de conscientização de alunos, direcionada a explicar que o uso de celulares é prejudicial para a interação docente/aluno e que, portanto, eles deveriam restringir seu uso. Certamente, desta vez, eles foram além do puramente moral: recorreram ao Direito e o motivo é claro, pois os docentes partem da base de que o simples exercício de conscientização sobre o não uso de celulares em sala de aula é insuficiente para

\footnotetext{
${ }^{20}$ O Plano Político Pedagógico está no Blog da escola. Agradeço a colaboração da Professora Flavia Elisa Schmitt da Cruz que gentilmente postou este documento para contribuir com a realização do presente trabalho. Veja Escola...(2014).

${ }^{21}$ Não somente os professores da Escola Alinor Vieira Corte, mas todos os professores das diferentes escolas que interroguei ao longo da minha última visita como tutor, relataram sobre diversas más experiências com o uso de celulares por parte dos alunos em sala de aula foram muitos. Todos me contaram com bastante decepção sobre os muitos casos infrutíferos, nos quais eles pediram de forma amigável para um aluno não usar seu celular em sala de aula. Todos afirmaram que, na grande maioria das vezes, chamar a atenção do aluno e simplesmente "pedir" para ele não se conectar a WhatsUp ou Facebook não é suficiente. Isso é mais uma evidência do "quadro pós-disciplinar" no marco da Educação do qual Fisher (2009, p. 23) fala.
} 
resolver o problema.

Como resultado da aplicação da nova medida, os professores da escola relataram que alguns pais tiveram que visitar semanalmente a direção da instituição para retirar os celulares dos seus filhos, ou seja, muitos alunos continuaram utilizando seus celulares em sala de aula, apesar da multa de R $\$ 30,00$ que seus pais tiveram que pagar em mais de uma ocasião. Mesmo assim, a medida foi considerada exitosa por parte dos docentes da escola. Exceto em alguns casos pontuais, ela parece ter cumprido com seu propósito prático principal.

A partir dos depoimentos dos professores das escolas que visitei, cabe concluir que o diagnóstico referente às escolas no Brasil não difere muito do diagnóstico das instituições de ensino britânicas apresentada por Fisher. Trata-se de uma situação na qual os alunos não conseguem resistir à tentação de estar constantemente conectados a aparelhos celulares, principalmente, para se conectar a redes sociais. Por causa disso, os professores das escolas que acompanho estão numa curiosa situação — da mesma forma que outros tantos professores do país e do mundo inteiro. Por um lado, eles devem utilizar e fomentar o uso da tecnologia digital no processo educativo visando à melhora dos currículos das instituições nas quais eles trabalham. No curso que estão realizando, eles são capacitados para, entre outras coisas, valorizar o uso das TICs em sala de aula. Por outro lado, existe em todos eles uma profunda rejeição pelo uso indiscriminado de celulares por parte dos alunos. Em outras palavras, eles procuram aproveitar um número significativo de aparelhos eletrônicos na hora de dar sua aula — computadores, lousa digital, projetores etc.- mas, ao mesmo tempo, sofrem os efeitos colaterais de uma geração de crianças e adolescentes que não consegue se desgrudar de seu "matrix de bolso". Eis o problema de vivermos num tempo em que uma quantidade expressiva de indivíduos consegue e até sente a necessidade de se manter conectado vinte e quatro horas do dia, inclusive em plena aula, sob pena de se sentir perdido ou desconectado do mundo.

\section{VISANDO UMA ÉTICA CRÍTICO- CONSEQUENTE NO USO DA TECNOLOGIA DIGITAL}

Na primeira parte deste trabalho, abordei algumas das características da nossa cultura digital. $\mathrm{Na}$ segunda parte, apresentei uma reflexão sobre o impacto da tecnologia digital na educação. Nessa última seção, procurarei expor algumas reflexões com o objetivo de discutir os resultados da investigação.

\section{Acrítico, acrático e crítico consequente}

A fim de compreender o objetivo principal deste trabalho é preciso esclarecer o que se deve entender por um uso crítico consequente da tecnologia digital. Nesta seção, pretendo fazer tal análise a partir da distinção entre os conceitos de "crítico consequente", "acrítico" e "acrático".

(1) Em primeiro lugar, especificarei o que se deve entender por um uso acrítico das tecnologias digitais. Em algumas ocasiões ao longo do texto, empreguei esse conceito sem maiores esclarecimentos, mas, neste momento, é necessário apresentar algumas considerações a seu respeito.

Fazendo uma breve análise linguística e etimológica, o adjetivo acrítico aplica-se àquilo que não é crítico. E se por crítica entendemos opinião reflexiva -isto é, não opinião no sentido grego de $\delta o ́ \xi \alpha$, ou seja, mera opinião daqueles que não têm o $\lambda$ ó $\mathrm{s}$ - o acrítico é aquilo que não obedece a uma reflexão aprofundada prévia. Dessa forma, acrítico é o comportamento - a ética- de uma pessoa que come de forma compulsiva alimentos gordurosos sem previamente ter parado para refletir sobre os conhecidos efeitos de uma alimentação não saudável rica em lipídios. Entretanto, o caso que utilizaremos como exemplar é o ethos do fumante. Imaginemos uma pessoa que tem fumado por muitos anos e que, interpelado por seus seres queridos pela sua conduta autodestrutiva, responde que não se importa com esse tipo de coisas. Toda vez que ele escuta alguém lhe aconselhar que deve parar de fumar pelo seu bem, demonstra não se importar pela sugestão da outra pessoa. No máximo, apela para respostas clichês como petições de princípios do tipo: "todos temos a nossa hora para morrer", "todos temos um destino do qual não podemos escapar”. Com esse 
tipo de argumento falacioso, a pessoa pode passar por alto - mesmo que de forma inconscientede uma reflexão aprofundada sobre sua conduta autodestrutiva. Em outras palavras, a pessoa não reflete sobre os efeitos de fumar e continua fumando sem sentir que está levando uma ética nociva para sua saúde.

$\mathrm{O}$ que esta reflexão sobre o conceito de "acrítico" oferece ao contexto deste trabalho? No marco da cultura digital, podemos identificar que um indivíduo faz um uso acrítico da tecnologia digital e de redes sociais quando ele não reflete sobre eventuais efeitos negativos que seu ethos pode lhe provocar. Da mesma forma que no suposto caso do fumante, ele pode apelar para argumentos como: que ele não está o tempo todo conectado a uma rede social -mesmo quando passa mais da metade do dia conectado ao Facebook em seu smartphone-, que isso não é prejudicial para sua saúde, ou que isso não acarreta nenhum tipo de inconvenientes com o(a) parceiro(a), sua família e seres queridos que interagem de forma direta com ele -isto é, sem a intermediação da tecnologia digital. É o caso daquelas pessoas que desistem de atividades ao ar livre, tais como ir à praia, porque a bateria do seu smartphone não está completamente carregada e as praias — pelo menos ainda- não possuirem tomadas para conectar aparelhos elétricos, e acham que isso é totalmente normal. Nesse caso, sustento que o sujeito leva adiante uma forma de vida irreflexiva. Com seus hábitos, ele pode acarretar problemas diversos —na família, no trabalho, de saúde- e mesmo assim, não percebê-lo. Essa é uma pessoa que incorporou de forma totalmente acrítica um ethos muito próprio da nossa cultura digital, como aqueles tantos mobile lovers que não fazem parte da pintura de Banksy, mas do nosso mundo real.

Muitos podem ser os casos em que podemos evidenciar que um sujeito faz um uso acrítico das tecnologias digitais. Contudo, como foi apresentado na introdução do trabalho, não se trata de uma crítica moral desses sujeitos. Em outras palavras, não defendo a tese extrema de que esse tipo de sujeitos incorre num ato verdadeiramente imoral, dado que não respeita certos deveres morais ${ }^{22}$. No entanto, gostaria

\footnotetext{
${ }^{22}$ Não obstante, afirmo que esse tipo de tese pode perfeitamente ser defendida, por exemplo, apelando para uma moralidade do tipo kantiana, entendendo que os seres racionais possuem deveres morais para consigo mesmos.
}

de abordar um ponto em especial acerca da questão moral.

$\mathrm{Na}$ primeira parte do trabalho, apresentei o dado sobre uma alta porcentagem de usuários de Facebook menores de 13 anos, algo contrário à política da própria empresa. Mencionei também, na segunda parte, os problemas existentes nas escolas associados ao uso de celulares por parte dos alunos. Resulta claro que nossa cultura digital oferece prazeres a uma vasta gama de usuários, inclusive crianças. Desse modo, podemos apreciar como nossa cultura lança ao mercado uma grande quantidade de produtos e serviços visando atingir o mercado das crianças. Hoje, existe a possibilidade de que até os bebês experimentem prazeres sensoriais, por exemplo, assistindo um vídeo de Peppa Pig — desenho animado britânico que data de 2004 e que só há poucos anos tornou-se furor na América Latina-, e que as crianças de uma idade mais avançada possam experimentar a máxima alegria de poder brincar, - por exemplo, com o último Playstation lançado pela Sony. As crianças, na perspectiva do mercado, são vistas como meros alvos. Quando um técnico de marketing de uma empresa de brinquedos pensa numa criança, ele não se importa com suas necessidades — que ela precisa receber uma educação apropriada, que ela precisa praticar esportes etc. Ele só enxerga na criança um alvo. Em termos mais apropriados da esfera da Economia, as crianças são um mero púbico objetivo a partir do qual se pode obter um lucro. Dessa maneira, o mercado, assim como faz com os adultos, se serve desses seres, por natureza, acríticos, para obter lucro, sem se preocupar com suas necessidades.

Neste momento, alguns poderiam pensar que, a seguir, utilizarei as categorias marxianas para fazer uma crítica cliché ao mercado e a sua falta de compromisso moral, dado que ele não leva em consideração as necessidades das crianças. Contudo, não é esse o caso. O que pretendo destacar é a falta de compromisso moral apresentada por todos aqueles pais que, de forma totalmente acrítica, permitem a seus filhos experimentar esses prazeres clássicos da nossa

Concretamente, no marco da ética kantiana, os seres racionais possuem o dever de desenvolver seus talentos (KANT, 2007). Sendo assim, se o fato de estar grande parte do dia conectado a uma rede social significa um empecilho para desenvolver talentos -impedindo que o sujeito estude, treine alguma arte, ofício ou profissão- desde a lógica kantiana, ele seria considerado como um verdadeiro fato imoral. 
cultura digital anteriormente referidos. Certamente, inseridos como estamos na lógica capitalista, não há muito que se possa fazer contra a lógica do mercado, além de uma completa revolução. Da mesma forma que acontecia quando Marx escreveu $O$ capital, o mercado ainda segue produzindo mercadorias visando seu valor de troca. Isso não impede, porém, que, no processo de educação de seus filhos, os pais consigam refletir sobre as necessidades das crianças e agir de forma consequente e responsável. Assim, mesmo que possamos compreender que a lógica do nosso mercado foi e sempre será, de certa forma, perversa também com as crianças, cabe a todo pai ou tutor educar seu filho ou tutorando de uma forma reflexiva em relação ao uso de tecnologia digital. Isso, muitas vezes, pode significar, por exemplo: impedir que seu filho esteja o dia todo jogando videogame e deixando de lado suas tarefas da escola, não fornecer um telefone celular ao seu filho logo após ele ter superado o estágio de bebê, ou simplesmente não permitir que a criança deixe de fazer atividades que não envolvam o estímulo de tecnologias digitais.

Resumindo: toda criança é, por natureza, acrítica e, portanto, não possui a capacidade de agir de forma plenamente responsável. No entanto, cabe ao pai o compromisso moral de cuidar das necessidades dos seus filhos, as quais, muitas vezes podem implicar a não exposição parcial ou total de alguns estímulos produzidos pelas tecnologias digitais. O pai tem um dever com seu filho, a saber, educá-lo de forma adequada — com tudo o que isso puder significar. Portanto, ele tem o compromisso moral de cuidar e incentivar o desenvolvimento de hábitos - a éticado filho, o que só conseguirá fazer desde que aja com um alto grau de criticismo e responsabilidade.

(2) Em segundo lugar, passarei a definir o sentido do conceito acrático. Utilizo-o no sentido estrito empregado por Aristóteles (1991) como aquilo que conjuga a partícula " $\alpha$ ” — que denota negação- e o

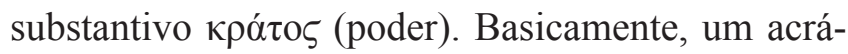
tico é aquela pessoa que, mesmo tendo consciência plena dos seus verdadeiros interesses, não consegue agir de forma consequente. Voltemos para o exemplo de um fumante. Imaginar o caso de uma pessoa que, após anos consumindo cigarros, percebe que, pelo bem da sua saúde, deveria parar de fumar, mas que mesmo assim, não consegue fazê-lo. Trata-se de uma pessoa que reflete de forma apropriada sobre o problema em questão e que, todavia, não consegue mudar sua ética.

Uma das principais características da pessoa acrática é que ela sofre de forma dupla. Em primeiro lugar, sofre as consequências diretas da sua ética nociva. Mas o acrático também sofre pelo fato de não poder mudar seus hábitos. Em outras palavras, ele não somente sofre os efeitos diretos da sua prática, mas também experimenta o sentimento de impotência de não poder levar adiante uma forma de vida alternativa. Voltando ao caso do nosso fumante imaginário, ele sofre os efeitos físicos do cigarro em seu organismo. Ademais, ele pode experimentar também o forte sentimento de tristeza por não ser capaz de parar de fumar ${ }^{23}$.

E o que seria um uso acrático das tecnologias digitais e das redes sociais? Trata-se daqueles casos nos quais a pessoa, seja por instrução externa, seja por pura reflexão pessoal, percebe que, por exemplo, seu costume de dedicar muitas horas às atividades que acontecem nas redes sociais através de seus celulares, smartphones, computadores etc., está lhe acarretando problemas no trabalho e fazendo que disponha menos tempo ao longo do dia para a prática de esportes, mas que, mesmo assim, não consegue resistir à tentação de se conectar constantemente. A pessoa pode claramente perceber que ela não deveria estar tanto tempo envolvida com seus "parceiros digitais", contudo, não consegue desligar seu celular nem por um minuto. Essa é a figura de um verdadeiro acrático.

Uma vez especificado o que se entende por sujeito acrático, cabe nos perguntarmos se os acráticos são, estritamente, indivíduos acríticos. Essa resposta é decisiva para os fins do presente trabalho.

Como já mencionei, o acrático se caracteriza por não conseguir agir segundo sua escala de valores. Mas, certamente, o acrático consegue criar uma ótima escala de valores. Este sujeito consegue ponderar de forma apropriada entre vias de ação incompatíveis.

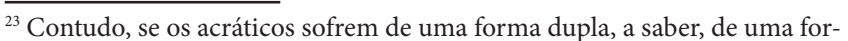
ma direta e por se sentir impotentes de mudar seus costumes, isso poderia nos levar à precipitada conclusão de que é melhor ser um acrítico do que um acrático, dado que aquele sofre apenas de forma direta. No entanto, o acrático conta com a sorte de que esse sentimento adverso que sente por não poder superar seus hábitos é a chave para que ele procure uma saída ao problema. Sendo assim, um acrítico pode passar a vida toda sem perceber que deveria mudar seu comportamento. No caso do acrático, ele pode capitalizar seu sentimento de tristeza perante o problema para tentar achar uma saída, seja de forma puramente pessoal, seja procurando ajuda externa etc.
} 
Em outras palavras, o acrático é um ser absolutamente crítico; ele é um ser reflexivo. É claro que se pode chegar a afirmar que certos acráticos podem ter agido de forma acrítica em um tempo passado, como é o caso de muitos consumidores drogas com forte capacidade aditiva. No preciso momento em que ele adquiriu determinado vício, pode não ter refletido da forma apropriada. $\mathrm{O}$ argumento estaria baseado no fato de que se o indivíduo tivesse parado para refletir sobre esse primeiro passo que ia dar ao consumir uma determinada droga pela primeira vez, ele poderia ter chegado à conclusão de que, segundo seus interesses, ele não deveria prová-la. Contudo, após ter adquirido o vício em questão e uma vez que o indivíduo sofre de forma interna por perceber que cometeu um erro e que deveria se afastar desse tipo de prática, não é possível concluir que estejamos frente a um sujeito acrítico.

Não há dúvidas de que o comportamento acrático é próprio de pessoas críticas e isso também se aplica àqueles sujeitos acráticos que não conseguem superar condutas compulsivas no uso de tecnologia digital. Mas, é claro, nem todos os sujeitos críticos são acráticos. Esse será o objeto da próxima análise.

(3) Uma vez explicitados os motivos pelos quais se pode entender o acrático como um sujeito crítico, é possível explicar de forma mais simples em que consiste o "uso crítico consequente das tecnologias digitais".

Definirei aquilo que entendo por comportamento crítico consequente de uma forma predominantemente negativa, ou seja, para especificar a natureza do meu objeto utilizarei como metodologia explicitar, primeiramente, aquilo que ele não é. Dessa forma, o ser aparecerá de forma mais clara pelo contraste com seu não ser.

Certamente, não será preciso aprofundar a ideia de que aquilo que é crítico consequente não pode ser considerado ao mesmo tempo como acrítico. Quando discuti esse último conceito, procurei mostrar que ele consiste no oposto de crítico. Entretanto, cabe esclarecer qual é a sua relação com aquilo que é acrático. Para isso, é necessário assumir que os comportamentos críticos podem ser de duas formas: ora acráticos, ora críticos consequentes. Dessa forma, um comportamento é crítico consequente quando, entre outras coisas, o mesmo deriva de uma reflexão aprofundada por parte do sujeito. Em outras palavras, esse tipo de ética tem lugar quando a pessoa reflete de forma aprofundada sobre seus interesses e necessidades e consegue agir da forma apropriada. Como exemplo, esse é o tipo de ética de uma pessoa que pratica esportes na medida certa, dado que ela entende que isso contribui com sua saúde e não tem o hábito de consumir drogas, porque ela sabe que se provasse alguma droga pesada, poderia se tornar dependente. Voltando ao caso do vício de fumar, uma pessoa age de forma crítica consequente quando se priva da experiência de consumir um cigarro, nem que seja uma só vez, porque reconhece que isso pode ser o começo de uma ética nociva para sua saúde.

A partir das observações feitas ao longo do presente trabalho, defendo como tese central que os homens inseridos na cultura digital devem - sem que esse "devem" dê a minha tese uma conotação moralizante - fazer um uso crítico consequente das tecnologias digitais e das redes sociais ${ }^{24}$. Com isso, afirmo de forma explícita que não sou contrário a que os homens utilizem as úteis ferramentas que estão disponíveis em nossa cultura digital, sob pena de cair num conservadorismo romântico insensato. $\mathrm{O}$ que neste trabalho defendo é que nem todo uso dessas ferramentas deve ser motivado ou considerado inofensivo, aceitável, natural etc. De forma reflexiva, cada um de nós pode avaliar qual é o tipo e uso mais apropriado de nossos celulares, computadores, redes sociais etc.

\section{Reflexões finais}

Todos nós somos testemunhas de que, nos últimos anos, o uso quase irrestrito de aparelhos eletrônicos associados à comunicação tem causado o efeito colateral de entorpecer a comunicação direta entre aquelas pessoas que estão numa mesma sala, seja dividindo um jantar familiar, ou inclusive entre os convidados de uma festa. Um número cada vez maior de pessoas transita nas ruas, nos metrôs, nos aeroportos das cidades, conectados a aparelhos celulares, abstraídos do mundo que os circunda. São esses zumbis urbanos que diariamente aumentam o

\footnotetext{
${ }^{24}$ É claro que o imperativo ético de sermos críticos consequentes não tem por que ser aplicado de forma exclusiva ao uso das tecnologias digitais. Certamente, cabe percebermos que o uso de tecnologia digital é somente um dos muitos exemplos nos quais se evidencia a necessidade desse tipo especial de criticismo.
} 
risco de perderem suas vidas num acidente de trânsito por causa de uma conexão.

Quem mora numa construção de mais de quinze anos, sente na pele o fato de que foram planejadas com, no máximo, duas tomadas elétricas por sala. Mas nossa era digital exige que cada sala deva possuir uma quantidade de tomadas muito maior. Roteadores, celulares, câmeras, notebooks, tablets, elementos todos que disputam no dia a dia o número de tomadas da casa.

Máquinas: computadores, celulares, smartphones, tablets, câmeras... São simples mercadorias. E já dizia Marx que:

As mercadorias não podem ir por si mesmas ao mercado e trocar-se umas pelas outras. Temos, portanto, de nos voltar para seus guardiões, os possuidores de mercadorias. Elas são coisas e, por isso, não podem impor resistência ao homem (MARX, 2013, p. 159).

Podemos continuar o raciocínio de Marx e dizer também que as mercadorias tampouco querem nos fazer dano: elas não querem que nós desenvolvamos o vício de utilizá-las o tempo todo, elas não planejam formas de nos fazer sentir dependentes delas. Mais uma vez, devemos virar nosso olhar para os "guardiões" dessas mercadorias. Por trás desse novo ethos tecnológico do homem inserido na cultura digital, existem pessoas que se beneficiam pelos novos hábitos da(s) nossa(s) sociedade(s). São aqueles que desejam que compremos todos os dias a nova versão do I-phone, aqueles que querem que estejamos conectados todo o tempo ao Facebook para vender os espaços publicitários do sitio web a um preço melhor. Contudo, esses são os interesses de um número muito restrito de empresários no mundo. Cabe agora saber quais são os interesses daqueles usuários que, diariamente, são motivados a se conectar entre eles através do mundo virtual.

Esse é o mundo que nós construímos e do qual fazemos parte. Esse é o verdadeiro ser do nosso universo. Mas isso não significa, porém, que deva ser assim. A aceitação do ser como o dever ser é a melhor expressão de uma cultura que se reproduz diariamente, não já numa mudança de época, senão numa época de mudanças, de forma acrática e acrítica. Num interessante artigo sobre o uso das TICs, o Professor José Carlos Antonio afirma:
[N]em adianta criticar esse "mundo novo" porque na maioria das vezes a crítica acaba sendo hipócrita, como a crítica do professor que condena seus alunos por levarem o telefone celular na escola, mas que não tira o próprio celular da bolsa porque sabe o quanto ele é útil e divertido. Que critica o aluno que não faz tarefas de casa, e ao invés disso fica horas na internet, mas, ele mesmo, não prepara muito aulas e passa horas no Orkut, cuidando de sua "colheita feliz" ou atirando passarinhos contra obstáculos (ANTONIO, 2012).

Esse é o típico argumento de um professor comprometido com o uso das tecnologias digitais na Educação. O problema é que ele incorre numa clara falácia. Afirmar que "nem adianta criticar esse 'mundo novo' porque na maioria das vezes a crítica acaba sendo hipócrita" é algo simplesmente insustentável: se partimos da premissa de que "na maioria das vezes a crítica [de um professor] acaba sendo hipócrita", dela não se segue que "nem adianta criticar esse 'mundo novo"'. Ademais, o professor Antonio evidencia não cogitar na possibilidade de que todos esses críticos aos quais ele rotula de hipócritas sejam, na realidade, meros sujeitos acráticos: sujeitos que enxergam de forma clara o mal que produz nas pessoas o hábito de estar conectado o tempo todo, mas que não conseguem se desgrudar de uma máquina.

Indo na direção oposta do professor Antonio, eu afirmo de forma enfática que esse mundo novo deve ser necessariamente criticado, muito criticado, no sentido pleno da palavra, porque somente criticando esse novo mundo é que nos tornamos seres críticos. $\mathrm{O}$ ato reflexivo e crítico é aquilo que nos torna pessoas esclarecidas que sabem o que querem. Caso não façamos isso, seremos somente meros consumidores de mercadorias -o grande desejo de muitos "guardiões"!

Cabe destacar que não se trata de negar que a tecnologia digital possa ser, em muitos aspectos, útil e necessária. Tampouco se trata de cair no discurso e nos remeter a uma espécie de época dourada, na qual tudo era melhor porque não existiam tecnologias digitais para acabar com a nossa saúde mental. Esse tipo de romantismo pouco contribui. Não se trata de a tecnologia da qual dispomos no nosso dia a dia ser intrinsecamente prejudicial. $\mathrm{O}$ ponto que quero destacar, apenas, é que não devemos fazer um uso acrático ou acrítico das mesmas. Não é possível 
negar os muitos benefícios que disfrutamos por ter a nossa disposição toda essa tecnologia. A Medicina, a Educação, o Transporte e muitos outros aspectos da vida humana, não seriam os mesmos sem a existência da tecnologia digital. Mas isso não torna toda essa tecnologia boa em si. Em outras palavras, a tecnologia, seja a tecnologia digital ou qualquer outra, é boa como um meio para a satisfação de certos desejos e necessidades. Entretanto, ela pode passar a desenvolver um papel perverso em nossas vidas, caso não saibamos lidar com ela. A mesma tecnologia que pode nos comunicar com familiares e seres queridos que estão do outro lado do planeta, também pode ser uma poderosa fonte de verdadeiros vícios. Assim, a linha que separa o ser humano crítico que utiliza a tecnologia em seu benefício, do sujeito -e, enquanto sujeito, sujeitado- que se conecta a aparelhos eletrônicos de forma constante e movido pelo vício, parece difusa, mas ela existe.

Com base nos fatos observados e relatados no presente artigo, cabe a nós decidir qual será nossa atitude em relação ao uso das novas tecnologias. A esse respeito, a Psicóloga Pilar Sordo nos oferece o seguinte conselho:

Tenemos que entender que la tecnología es una herramienta y que la tengo que regular en beneficio mío. Es maravillosa, pero no puede remplazar lo real [...] La búsqueda del equilibrio y la fuerza de voluntad son la única salida a esta situación, que de lo contrario, nos terminará consumiendo a todos. Es fácil caer en este sistema que te entrega información todo el tiempo y estar permanentemente conectado. Sin embargo esto no es lo mismo que estar comunicado (SORDO, 2013).

"A tecnologia [digital] é uma ferramenta" e, portanto, seu uso deve nos beneficiar. Caso isso não aconteça, devemos desligar nossos computadores, celulares, smartphones e correr atrás da nossa felicidade. Caso não façamos isso, estaremos trocando meios por fins.

\section{Referências bibliográficas}

ANTONIO, José Carlos. Educação, TICs e diversão. Professor Digital, 08 jan. 2012. Disponível em: <https://professordigital.wordpress.com/2012/01/08/ educacao-tics-e-diversao/>. Acesso em: 17/11/2014.
ARISTÓTELES. Ética a Nicômaco. São Paulo: Nova cultural, 1991.

BANKSY'S Mobile Lovers: Youth club owner who sold artwork in Bristol receives death threats. The Independent. 27 de ago. 2014. Disponível em: <http://www.independent. co.uk/arts-entertainment/art/news/banksy-mobile-loverssold-owner-of-youth-club-where-artwork-appeared-inbristol-received-death-threats-9695327.html>. Acesso em: 12/11/2014

BRAGA, Sérgio. $O$ uso da internet nas campanhas eleitorais: o balanço do debate e algumas evidências sobre o Brasil. Revista USP, Brasil, n. 90, p. 58-73, ago. 2011. ISSN 2316-9036. Disponível em: $<$ http://www.revistas.usp. br/revusp/article/view/34012/36746>. USP, São Paulo, n.90, p. 58-73, junho/agosto 2011. Acesso em: 17 nov. 2014.

BRASIL. Resolução no 23399, de 03 de abril de 2014. Dispõe sobre os atos preparatórios para as Eleições de 2014. Brasília, DF, 25 jan. 2008. Disponível em: <http://www. tse.jus.br/eleicoes/eleicoes-2014/normas-e-documentacoes/ resolucao-no-23.399>. Acesso em: 12 nov. 2014.

ENEM 2014: MEC elimina 65 candidatos por uso indevido de celulares. Veja. São Paulo, 08 nov. 2014. Disponível em <http://veja.abril.com.br/noticia/educacao/enem-2014mec-elimina-65-candidatos-por-postarem-fotos-de-provas $>$. Acesso em: 12/11/2014.

EQUINOTERAPIA, oportunidad y esperanza de rehabilitación (2012) HDsrl. 2012. (18 min.), son., color. Disponível em $<$ https://www.youtube.com/watch? $\mathrm{v}=\mathrm{sNYkttVKzck>}$. Acesso em: 19/11/2014.

ESCOLA ALINOR VIEIRA CORTE. Plano Político Pedagógico. 2014. Disponível em $<$ https://drive.google. com/file/d/0B4iqlA00_YDSTmhDSnBRSnFZQ1E/view>. Acesso em: 15/11/2014.

FACEBOOK mostra o raio-x de 1 bilhão de usuários. Folha de S. Paulo. 04 out. 2012. Disponível em: <http://www1. folha.uol.com.br/tec/2012/10/1163808-facebook-mostrao-raio-x-de-1-bilhao-de-usuarios.shtml>. Acesso em: $12 / 11 / 2014$

FISHER, Mark. Capitalist realism: is there no alternative? Washington: Zero Books, 2009.

FOX, Jeffrey. Five million Facebook users are 10 or younger. ConsumersReport.org. 10 mai. 2011. Disponível em: <http://www.consumerreports.org/cro/news/2011/05/ five-million-facebook-users-are-10-or-younger/index.htm>. Acesso em: 12/11/2014.

GOOGLE Glasses Project. 2012. (2 min.), son., color. Disponível em: <https://www.youtube.com/ watch?v=JSnB06um5r4>. Acesso em: 13 nov. 2014.

GOOGLE Glass Sucks! 2013. (3 min.), son., color. Disponível em: <https://www.youtube.com/watch?v=4_X6EyqXa2s $>$. Acesso em: 13 nov. 2014. 
JETSONS_entremeios.wmv. 2011. (5 min.), son., color. Disponível em: <https://www.youtube.com/ watch?v=BpC3U_x6c6k>. Acesso em: 11 nov. 2014.

KANT, Inmanuel. Fundamentação da metafísica dos costumes. Lisboa: Edições 70, 2007.

MARX, Karl. O Capital: Crítica da economia política. São Paulo: Boitempo, 2013.

O BOTO cor-de-rosa, um golfinho da Amazônia, é o principal aliado de uma nova técnica de ter. 2011. (3 min.), son., color. Disponível em: <https://www.youtube.com/watch?v=cYUWpSh3xk>. Acesso em: 13 nov. 2014.

SANTA CATARINA (Estado). Lei n ${ }^{\circ} 14363$, de 25 de janeiro de 2008. Dispõe sobre a proibição do uso de telefone celular nas escolas estaduais do Estado de Santa Catarina. Lex. Florianópolis, SC, 25 jan. 2008. Disponível em: <http:// www.sed.sc.gov.br/secretaria/legislacao/cat_view/58legislacao/185-ensino/76-legislacao-estadual/82-leis $>$. Acesso em: 12 nov. 2014.

SORDO, Pilar. Estar conectado no es lo mismo que estar comunicado. 30 jan. 2013. Disponível em <http://www. pilarsordo.cl/plrsrd4/prensa/estar-conectado-no-es-lomismo-que-estar-comunicado $>$. Acesso em: 17/11/2014.

Recebido em: 20-11-2014

Aceito em: 12-03-2015 